\title{
AIR PORTABLE THOMAS SPLINT
}

\author{
Lieutenant-Colonel C. M. SAMUEL, \\ M.B.E., T.D., M.B., B.S., M.R.C.S., L.R.C.P., \\ M.R.C.G.P., D.P.H., D.I.H., R.A.M.C., S.A.V.R \\ Senior Medical Officer, 44 Parachute Brigade $(V)$
}

\section{The Problem}

The Thomas Splint remains a popular and useful item of medical equipment whether used alone or combined with plaster-of-paris. In Airborne operations it can be fixed on the stretcher bundle on the side of the weapon container for the parachute assault, but is not always appreciated by those carrying it. This is true at some other times when it is required to be man-handled over long distances, the shape encouraging some ingenuity in methods of carriage.

\section{The Stimulus}

An annual exercise for medical teams from the units of 44 Parachute Brigade, the Bruneval Cup, has been run by what was 44 Parachute Field Ambulance (TA), now incorporated in 144 Field Ambulance (V). Before the exercise at the end of 1966, which was just short of the 25th Anniversary of the raid on Bruneval, (February 1942, when an airborne medical team was first in action) the competition was livened up and given a new format, it being thought that over the years a stereotyped performance was being achieved. The revised competition was to start with a drop of the teams in sticks, from a balloon if the aircraft had to be cancelled, and this year the Cup was to be presented by the medical officer of the Bruneval raid, Major A. S. Baker.

In the event, meterological conditions prevented a descent even from a balloon, and the teams were motored on to the dropping zone. The hunted President of a friendly State temporarily overthrown was to be rescued and conveyed to safety, various incidents involving wounded guerillas being arranged on the way. After lying up during the night, there was a final river crossing at the frontier before the various team members were given individual viva voce examinations with slides, resuscitation models, instruments, or simulated casualties. These, as on the exercise, had been prepared by the Regimental Sergeant-Major of the Field Ambulance, W.O.I. Coomber.

The winning team contained no R.A.M.C. as such, but came from 44 Ordnance Field Park (TA) who had been trained in preceding weeks by their Permanent Staff Instructor and 44 Parachute Field Ambulance's Regimental Sergeant-Major. This team performed admirably and sensibly, and would indeed have had the President, in good condition, delivered to the friendly neighbouring State for surgery without being caught at the last minute at the frontier. Not so the medical team from one battalion, who delayed considerably by first ferrying across their Thomas splint (showing either the value they attached to this, or else a deep mistrust of their colleagues from other units) before going back for their President.

\section{The Reid Coomber Splint (44 Pattern Thomas)}

WO I. S. F. Coomber, R.A.M.C., of 44 Parachute Field Ambulance and WOII. R. Reid, R.A.O.C., the two Permanent Staff Instructors referred to above, had trained and led a fine team. Amongst other thoughts they applied themselves to consideration 


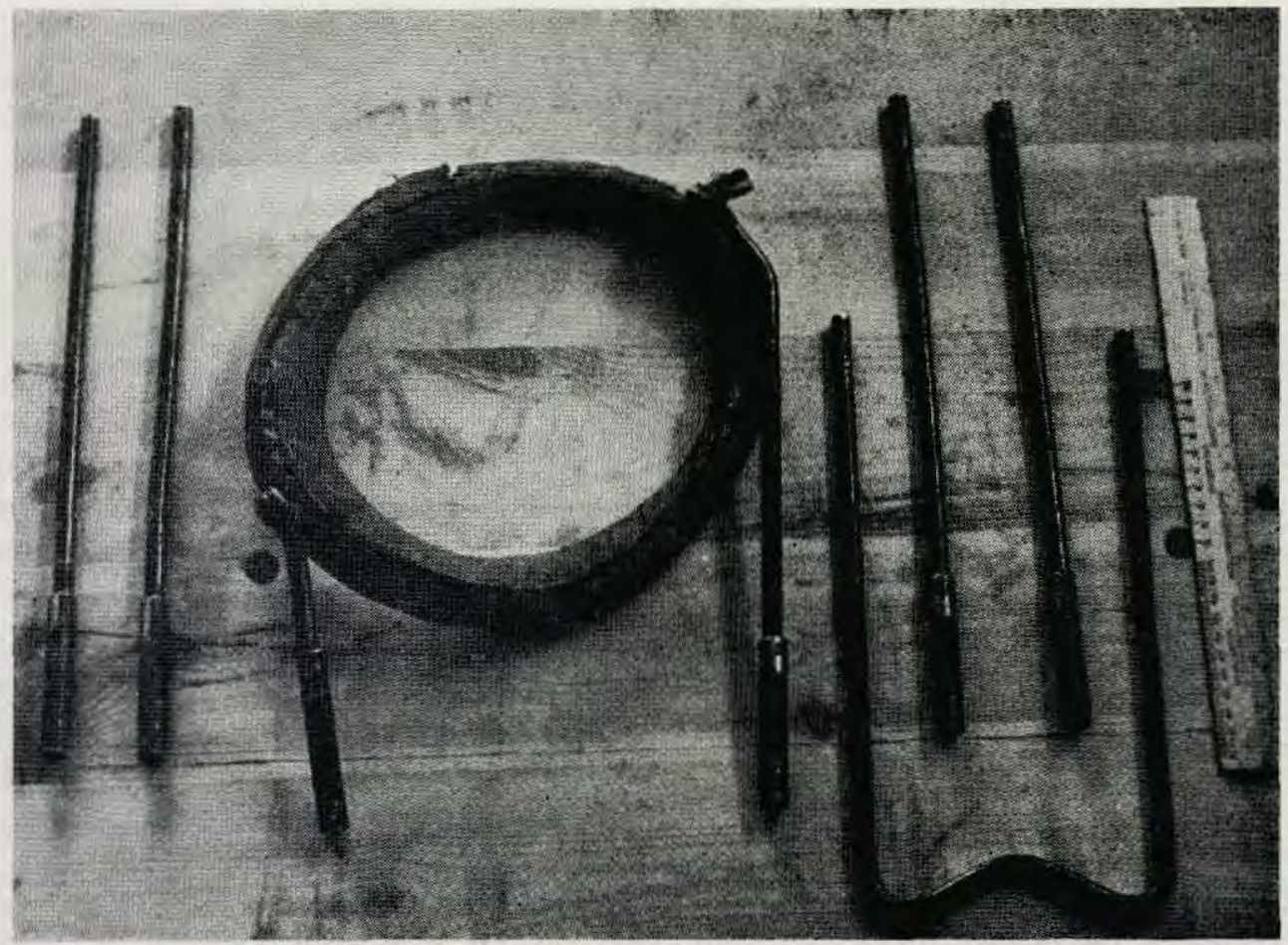

Fig. 1-The Reid Coomber Mark One.

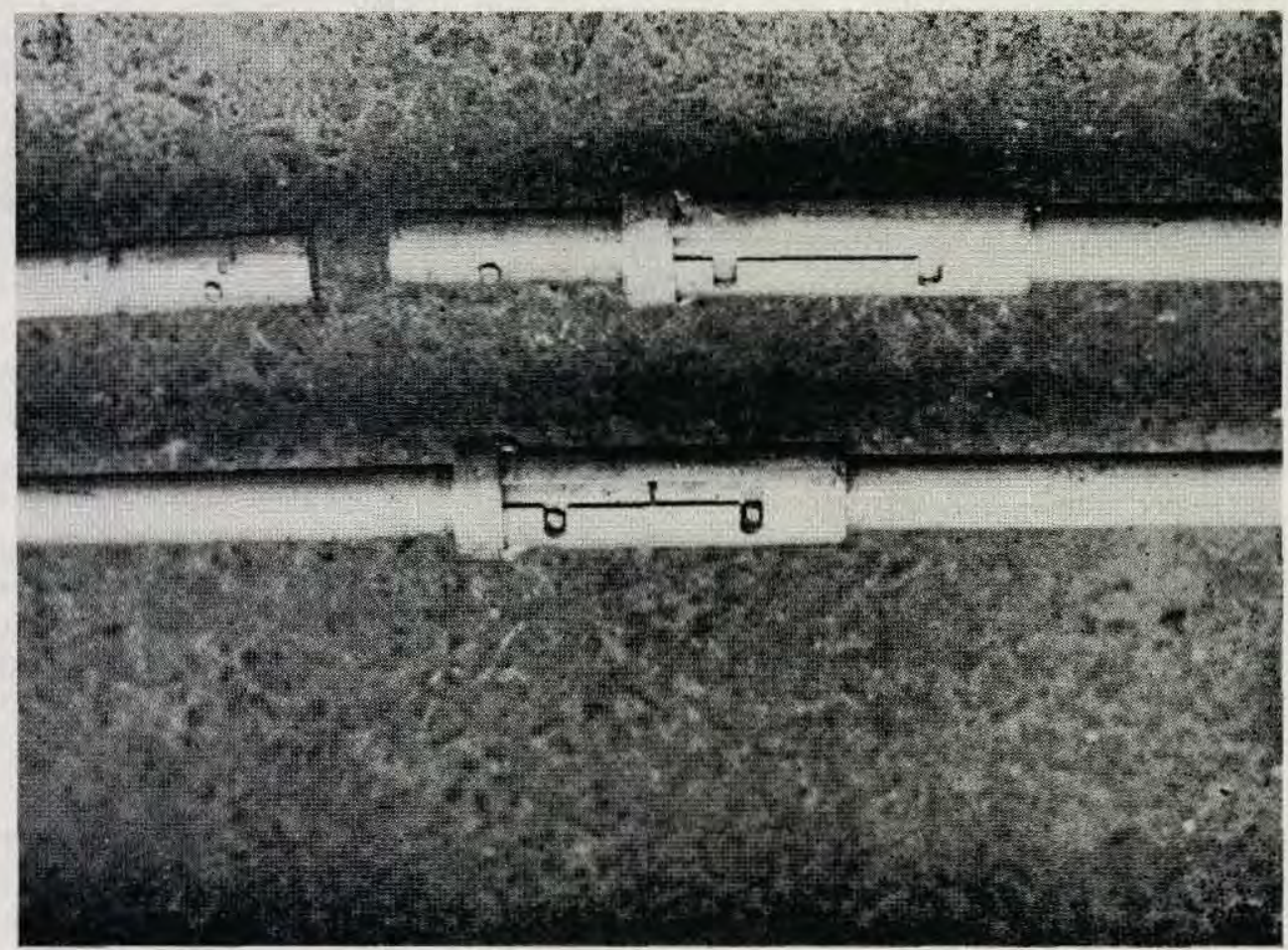

Fig. 2-The Airborne Sheiter joint. 
of the Thomas splint. The result of their deliberations, and Ordnance know-how, was a splint collapsible for carriage. The Mark I version of this was on the principle of the joints of the camp bed in current use, but with retaining pins (Fig. 1). The Mark II involves the principle of the twist lock of the later airborne shelter supports, which obviates the use of pins (Fig. 2). The result is a Thomas splint of suitable strength but capable of being broken down for packing in a variety of ways in to whatever is available for carriage. The proper application of the splint is not interfered with by jointings of this nature, or by the wing nut for the ring piece.

\section{Summary}

A variant of the Thomas Splint for ease of portability by WO I. S. F. Coomber, R.A.M.C., and WO II. R. Reid, R.A.O.C., is described and illustrated.

\section{Honorary Consultants}

Mr. Edward-Grainger Muir, M.S., F.R.C.S., has been appointed an Honorary Consultant in Surgery to the Army at Home in succession to Sir Arthur Porritt.

Mr. Muir is a surgeon to the Royal Household, and to King's College Hospital and Queen Victoria Hospital, East Grinstead. He is also a member of the Army Medical Advisory Board.

During the war Mr. Muir served as a Royal Army Medical Corps officer at home and in Palestine.

Mr. John Walter Sinclair Irwin, M.B., F.R.C.S.(Edin.), has been appointed Honorary Consultant in Surgery to the Army in Northern Ireland in succession to Sir Jan Fraser.

Mr. Irwin graduated M:B., B.Ch., B.A.O.(Honours) from Queen's University, Belfast in 1937 and is demonstrator in anatomy and tutor in the department of surgery at the University. He was formerly house physician and house surgeon at the Royal Victoria Hospital, Belfast, and surgeon-registrar at the Belfast City Hospital.

He was commissioned in the RAMC in October, 1939, joined the British Expeditionary Force in France in the following month, became a prisoner of war in the summer of 1940 and was repatriated in April, 1945.

Mr. John Herbert Hovell, T.D., M.R.C.S., L.R.C.P., F.D.S., has been appointed Honorary Consultant in Dental Surgery to the Queen Alexandra Military Hospital, Millbank, London. This is a new appointment.

Mr. Hovell graduated L.D.S., R.C.S. (Eng.), from the Royal Dental Hospital in 1931 and is honorary dental surgeon at the hospital and consultant dental surgeon at St. Thomas's Hospital. He was Hunterian Professor, Royal College of Surgeons of England, in 1950 and Tomes Lecturer in 1964. He is chairman of the Central Dental Consultants and Specialists Committee.

He transferred from the R.A.M.C. to the Army Dental Corps in 1940 and served as dental specialist in a maxillo-facial unit in India and Burma. 